\title{
Thermoplastic Polyurethane Elastomers with Aliphatic Hard Segments Based on Plant-Oil-Derived Long-Chain Diisocyanates
}

\author{
Brigitta Schemmer, Cathrin Kronenbitter, and Stefan Mecking*
}

Novel plant-oil-derived long-chain $\left(\mathrm{C}_{19}\right.$ and $\left.\mathrm{C}_{23}\right) \alpha$, $\omega$-diisocyanates, optionally in combination with the corresponding long-chain diols, provide entirely aliphatic hard segments in segmented thermoplastic polyurethane elastomers (TPUs), with carbohydrate-based poly(trimethylene glycol) soft segments. Compared to materials based on a mid-chain monomer analog, phase separation is higher due to an increased flexibility of the aliphatic segments. Although melting points are slightly lower than for HDPE, the long-chain TPU's solid-state structure is still dominated by hydrogen-bonding.

\section{Introduction}

Segmented thermoplastic polyurethane elastomers (TPUs) are versatile materials that have found a wide variety of applications ranging from textile fibers, adhesives, foams, coatings, and biomaterials. ${ }^{[1]}$ TPUs are linear multiblock copolymers composed of macrodiol soft segment blocks and urethane rich hard segment blocks. The incompatibility of hard and soft segment units results in phase separation with nanoscale hard segment domains dispersed in a continuous soft segment matrix. ${ }^{[2]}$ Typical macrodiols serving as soft segments are relatively long, flexible polyester or polyether diols with a molecular weight of 1000-3000 $\mathrm{g} \mathrm{mol}^{-1}$ like, for example, polycaprolactones and poly(tetramethylene glycol) which impart flexibility and ductility in TPUs. Hard segments that serve as load bearing phase are generally obtained by the reaction of diisocyanates with short diols, which produce polyurethane groups and include hydrogen bond formation between urethane groups thereby providing physical crosslinking. Commonly used monomers for hard segments are, for example, 1,4-butanediol as a short-chain diol and 4,4'-diphenylmethane diisocyanate (MDI) or toluene diisocyanate (TDI) as aromatic diisocyanate component. ${ }^{[3]}$ In order to increase UV-light stability, thermal stability and optical clarity aromatic diisocyanates can be replaced by aliphatic diisocyanates, for example, isophorone diisocyanate (IPDI) and 1,6hexane diisocyanate (HDI). ${ }^{[4,5]} \mathrm{A}$ class of aliphatic diisocyanates

B. Schemmer, C. Kronenbitter, Prof. S. Mecking

Chair of Chemical Materials Science

Department of Chemistry

University of Konstanz

Universitätsstrasse 10, D-78457 Konstanz, Germany

E-mail: stefan.mecking@uni-konstanz.de that has recently gained increasing interest are linear long-chain diisocyanates, which show potential for accessing a novel kind of TPUs combining the advantages of classical aliphatic TPUs with the possibility of exploiting polyethylene-like crystallinity. While linear diisocyanates containing up to 12 methylene units are commercially available, the synthesis of linear diisocyanates with longer methylene sequences up to eicosane diisocyanate ${ }^{[6 a-d]}$ has found less attention. While long-chain polyurethanes like PU-18,20 have been reported, thermoplastic elastomers with soft segments in combination with long-chain aliphatic crystalline segments are lacking.

To date, fatty acid derivatives are utilized for polyurethanes as polyol cross-linkers ${ }^{[5]}$ and soft portions. ${ }^{[6]}$ However, $\alpha, \omega$ difunctional linear long-chain compounds have recently become available from common seed oils or algae oils ${ }^{[7]}$ via biotechnological ${ }^{[8]}$ or chemical catalytic routes such as metathesis $^{[9]}$ or isomerizing alkoxycarbonylation. ${ }^{[10]}$ The long methylene sequences originating from complete incorporation of the entire fatty acid chain in these monomers provide access to novel long-chain monomers for long-chain aliphatic polycondensates. ${ }^{[11]}$ We now report the synthesis of novel linear longchain aliphatic diisocyanates based on oleic acid and erucic acid, and demonstrate their utility for the generation of all-aliphatic thermoplastic polyurethane elastomers.

\section{Results and Discussion}

\subsection{Monomer Synthesis}

Polyurethanes can be accessed by different routes, which have been reviewed comprehensively. ${ }^{[12]}$ Especially transurethanization of dicarbamates has been studied as an isocyanate-free route. However, this method often results in low molecular weight polyurethanes. ${ }^{[12 c]}$ In order to avoid this issue in favor of material properties we utilized the high reactivity of isocyanates in this work. Unsaturated fatty acids were utilized as a source for the preparation of linear saturated dibromo compounds which were used as precursors for the synthesis of novel linear long-chain diisocyanates via a nucleophilic substitution reaction (Figure 1). In the first step isomering alkoxycarbonylation of methyl oleate (1a) and ethyl erucate (1b) yielded dimethyl nonadecanedioate (2a) and dimethyl tricosandioate $(\mathbf{2 b}),{ }^{[13]}$ respectively, which were then reduced to obtain nonadecanediol 



Figure 1. Synthesis of fatty acid based 1,19-diisocyanatononadecane and 1,23-diisocyanatotricosane.

(3a) and tricosanediol (3b). ${ }^{[14]}$ In order to obtain the desired diisocyanates, the long-chain diols were converted into the corresponding dibromides $(4 \mathbf{a}, 4 \mathbf{b})$ via an Appel II reaction. ${ }^{[7]} \mathrm{A}$ subsequent nucleophilic substitution reaction with potassium cyanate based on a procedure reported by Schaeffer ${ }^{[15]}$ yielded nonadecane diisocyanate $(\mathbf{5 a})$ and tricosane diisocyanate $(\mathbf{5 b})$ in yields up to $40 \%$ (Figure 1). Unlike rearrangement reactions which are frequently used for the synthesis of fatty acid based linear diisocyanates ${ }^{[6 a, 16]}$ or dicarbamates, ${ }^{[17]}$ this kind of nucleophilic substitution reaction does not result in shortening of the hydrocarbon chain. Optimization of reaction conditions and work up procedure yielded the desired diisocyanates in sufficient yields and in polycondensation grade purity. The structure of the synthesized diisocyanates was confirmed via NMR and Fourier transform infrared (FTIR) spectroscopy. The FTIR spectra showed strong characteristic bands at $2260 \mathrm{~cm}^{-1}$ corresponding to the $\mathrm{N}=\mathrm{CO}$ stretching vibration (Figures $\mathrm{S} 4$ and S8, Supporting Information). ${ }^{1} \mathrm{H}$ and ${ }^{13} \mathrm{C}$ NMR spectra of the diisocyanates were in accordance with the proposed structures including a ${ }^{13} \mathrm{C}$ resonance at $\delta 122 \mathrm{ppm}$ characteristic of isocyanate groups and confirmed purity higher than $98 \%$ (Figures S1-S3, S5-S7, Supporting Information).

\subsection{Polymer Composition}

In order to synthesize segmented thermoplastic polyurethane elastomers, the obtained fatty acid derived long-chain diisocyanates $(\mathbf{5 a}, \mathbf{b})$ were copolymerized with the corresponding diols $(3 \mathbf{a}, \mathbf{b})$ and a macrodiol in a one-step solvent polymerization procedure. Thereby, the long-chain diisocyanates $(5 \mathbf{a}, \mathbf{b})$ and the corresponding diols $(\mathbf{3} \mathbf{a}, \mathbf{b})$ provide entirely aliphatic hard segments. As a macrodiol for the generation of soft segments carbohydrate-based poly(trimethylene glycol) with a molecular weight of $M_{n}=2000 \mathrm{~g} \mathrm{~mol}^{-1}\left(\mathrm{PPDO}_{2000}\right)^{[18]}$ was employed. Copolymerization of these monomers yielded entirely aliphatic TPUs with molecular weights of $M_{\mathrm{n}} 3$ to $5 \times 10^{4} \mathrm{~g} \mathrm{~mol}^{-1}$ according to end-group analysis from ${ }^{1} \mathrm{H}$ NMR spectroscopy. This is qualitatively confirmed by gel permeation chromatography (GPC) analysis which also shows well-behaved molecular weight distributions $M_{\mathrm{w}} / M_{\mathrm{n}}$ around 1.7. As typical for TPUs based on aliphatic polyurethane hard segments, the obtained copolymers are transparent and become more opaque with increasing content of hard segment (Figure 2 and Figure S9, Supporting Information). In order to further assess the effect of the long hydrocarbon chain of the aliphatic hard segments and compare these new hard segments with commercial hard segments, another polyurethane-polyether copolymer TPU$\mathrm{C}_{12} \mathrm{PPDO}_{2000}-59 \mathrm{wt} \%$ (Table 1, entry 7) was prepared which is based on the commercial mid-chain aliphatic monomers 1,12-diisocyanatododecane and 1,12-dodecanediol and contains a weight fraction of polyether diol comparable to TPU$\mathrm{C}_{23} \mathrm{PPDO}_{2000}-63 \mathrm{wt} \%$ (designation of the TPU materials list the monomer chain length of the hard block (e.g., $\mathrm{C}_{23}$ ), the molecular weight of the PPDO soft block (e.g., 2000), and the relative weight portion of soft block (e.g., 63\%, corresponding to $37 \mathrm{wt} \%$ hard block)). Apart from the fact that the shortest hard block, that is, an isolated diisocyanate repeat unit, is already twice as large for the long-chain monomer based polymer $\left(\mathrm{C}_{23}\right)$ compared to its mid-chain analog $\left(\mathrm{C}_{12}\right)$, their block length distributions and chain microstructure are similar. ${ }^{[19]}$

\subsection{Thermal Properties}

The DSC thermograms obtained for the synthesized long-chain TPUs feature two melting points, a low melting point in the range of -6 to $1{ }^{\circ} \mathrm{C}$ and a high melting point in the range of 62-116 ${ }^{\circ} \mathrm{C}$ (Table 1). These correspond to two domains formed by phase separation. The peak in the low temperature regime can be ascribed to soft segment melting while peaks in the

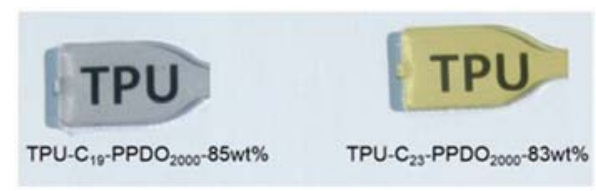

Figure 2. Optical appearance of injection molded test specimen of TPU$\mathrm{C}_{19}$ PPDO $_{2000^{-}} 85 \mathrm{wt} \%$ and TPU-C ${ }_{23}$ PPDO $_{2000^{-}} 83 \mathrm{wt} \%$. 
Table 1. Molecular weights and thermal properties of polyurethane-polyether copolymers based on mid-chain and long-chain aliphatic hard segments.

\begin{tabular}{|c|c|c|c|c|c|c|c|c|}
\hline Entry & Polymer & $\begin{array}{c}\mathrm{mol} \% \\
\mathrm{PPDO}_{2000} \\
\text { of total diol }\end{array}$ & $\begin{array}{c}\mathrm{M}_{\mathrm{n}}^{\mathrm{a})} \\
\left(\mathrm{NMR}^{-1}\right. \\
{\left[\mathrm{g} \mathrm{mol}^{-1}\right]}\end{array}$ & $\begin{array}{c}\mathrm{M}_{\mathrm{n}}^{\mathrm{b})} \\
(\mathrm{GPC}) \\
{\left[\mathrm{g} \mathrm{mol}^{-1}\right]}\end{array}$ & $\left.M_{\mathrm{w}} / M_{\mathrm{n}}^{\mathrm{b}}\right)$ & $\begin{array}{l}T_{\mathrm{m}}{ }^{\mathrm{c})} \\
{\left[{ }^{\circ} \mathrm{C}\right]}\end{array}$ & $\begin{array}{l}\left.T_{c}^{c}\right) \\
{\left[{ }^{\circ} \mathrm{C}\right]}\end{array}$ & $\begin{array}{l}\left.T_{\mathrm{g}} \mathrm{d}\right) \\
{\left[{ }^{\circ} \mathrm{C}\right]}\end{array}$ \\
\hline 1 & TPU-C ${ }_{19}$ PPDO $_{2000}-85 w t \%$ & $100 \%$ & $3.1 \times 10^{4}$ & $5.1 \times 10^{4}$ & 1.5 & $-1 / 62$ & $-18 / 32$ & -66 \\
\hline 2 & TPU- $\mathrm{C}_{19} \mathrm{PPDO}_{2000}-78 \mathrm{wt} \%$ & $75 \%$ & $3.2 \times 10^{4}$ & $4.5 \times 10^{4}$ & 1.7 & $-6 / 97$ & $-23 / 68$ & -68 \\
\hline 3 & TPU- $\mathrm{C}_{19} \mathrm{PPDO}_{2000}-67 \mathrm{wt} \%$ & $50 \%$ & $2.9 \times 10^{4}$ & $4.2 \times 10^{4}$ & 1.6 & $-6 / 109$ & $-31 / 78$ & -68 \\
\hline 4 & TPU-C $C_{23}$ PPDO $_{2000}-83 w t \%$ & $100 \%$ & $5.0 \times 10^{4}$ & $5.7 \times 10^{4}$ & 1.7 & $1 / 76$ & $-13 / 60$ & -68 \\
\hline 5 & TPU-C ${ }_{23}$ PPDO $_{2000}-75 w t \%$ & $75 \%$ & $3.0 \times 10^{4}$ & $3.9 \times 10^{4}$ & 1.7 & $-4 / 102$ & $-18 / 78$ & -69 \\
\hline 6 & TPU-C $\mathrm{C}_{23} \mathrm{PPDO}_{2000}-63 \mathrm{wt} \%$ & $50 \%$ & $3.3 \times 10^{4}$ & $4.1 \times 10^{4}$ & 1.7 & $-6 / 116$ & $-20 / 89$ & -69 \\
\hline 7 & TPU-C ${ }_{12}$ PPDO $_{2000}-59 \mathrm{wt} \%$ & $29 \%$ & $6.7 \times 10^{4}$ & - & - & 129 & 86 & -66 \\
\hline
\end{tabular}

a) Determined by end-group analysis from ${ }^{1} \mathrm{H}$ NMR spectroscopy; b) Determined by GPC in THF at $50{ }^{\circ} \mathrm{C}$ versus polystyrene standards; ${ }^{c}$ Determined by DSC with a heating/cooling rate of $10 \mathrm{~K} \mathrm{~min}^{-1}$; ${ }^{\mathrm{d}}$ ) Determined by DSC with a heating rate of $30 \mathrm{~K} \mathrm{~min}^{-1}$.

higher temperature regime can be ascribed to the melting of the hard phase. Partial replacement of the polyether macromonomer by the long-chain aliphatic diol $3 \mathbf{a}$ or $3 \mathbf{b}$, respectively, resulted in a significant increase of melt temperatures of the hard phase from 62 to $109{ }^{\circ} \mathrm{C}$ for $\mathrm{C}_{19}$-TPUs and 76 to $116{ }^{\circ} \mathrm{C}$ for $\mathrm{C}_{23}$-TPUs (Figure 3, Figures S13 and S14, Supporting Information).

This indicates more favorable crystallization conditions and an increased degree of ordering of the hard segment with increasing hard segment content. The same is true for replacing $\mathrm{C}_{19}$ long-chain monomers with corresponding $\mathrm{C}_{23}$ monomers, which results in increased melting temperatures of the hard phase and therefore higher melting points for $\mathrm{C}_{23}$-TPUs. Comparison of long-chain TPU-C ${ }_{23} \mathrm{PPDO}_{2000}-63 \mathrm{wt} \%$ with the analogous mid-chain TPU-C ${ }_{12} \mathrm{PPDO}_{2000}-59 \mathrm{wt} \%$ showed an increase in the melting temperature by $13-129^{\circ} \mathrm{C}$ which can be attributed to the higher content of urethane groups and the odd-even effect (Table 1, entry 7). If compared to analogous long-chain thermoplastic elastomers based on long-chain aliphatic polyester hard segments, the melting points of polyurethane-polyether copolymers are significantly enhanced due to hydrogen bonding between the urethane groups. ${ }^{[19]}$

Polycondensation of stoichiometric amounts of long-chain diisocyanate $\mathbf{5 a}$ and $\mathbf{5 b}$ with the corresponding long-chain



Figure 3. DSC thermograms (second heating) of polyurethane-polyether copolymers based on $\mathrm{C}_{19}$ monomers. diols 3a and 3b yielded PU-19,19 and PU-23,23, thermoplastic materials that showed melting points of 132 and $129{ }^{\circ} \mathrm{C}$ (Table S1, Figure S12, Supporting Information). As expected, the observed melting temperature decreases with increasing length of methylene sequences and therefore decreasing content of urethane groups due to reduced hydrogen bonding. Like for other long-chain polyurethanes ${ }^{[17,20]}$ the melting temperatures are close to and even below that for linear polyethylene $\left(T_{\mathrm{m}}=135^{\circ} \mathrm{C}\right) \cdot .^{[21]} \mathrm{Con}$ sidering the strong odd-even effects usually observed in the melting behavior of polyurethanes the melting points for PU-19,19 and PU-23,23 are surprisingly high. ${ }^{[2]}$ Compared to PU-18,20 $\left(T_{\mathrm{m}}=123^{\circ} \mathrm{C}\right)^{[17]}$ and PU-32,12 $\left(T_{\mathrm{m}}=135{ }^{\circ} \mathrm{C}\right)^{[20]}$ _polyurethanes with the same or almost the same content of urethane groups as PU-19,19 and PU-23,23, respectively-the melting points for PU-19,19 and PU-23,23 are in the same range and in case of PU-19,19 even higher than that for its even-even counterpart.

While PU-19,19 and PU-23,23 show no glass transition, all block copolymers studied show a glass transition point at $\approx-68{ }^{\circ} \mathrm{C}$ due to the PPDO soft segment. Glass transition temperatures of the soft-segment phase of all synthesized TPUs essentially resemble the $T_{\mathrm{g}}$ observed for the neat soft segment oligomer $\mathrm{PPDO}_{2000}\left(T_{\mathrm{g}}=-70{ }^{\circ} \mathrm{C}\right)$, in agreement with a virtually complete phase separation for all TPUs studied. ${ }^{[23]}$

\subsection{Mechanical Properties}

Tensile tests were performed on specimens prepared by piston injection molding. All segmented polyurethane materials show ductile behavior typical for thermoplastic elastomers and exhibit an elongation at break higher than $250 \%$ which increases to $490 \%$ with increasing polyether content (typical stresses at break are 4-7 $\mathrm{MPa}$ ). Segmented polyurethanes with hard segments based on $\mathrm{C}_{23}$ diisocyanate and diol instead of the corresponding $\mathrm{C}_{19}$ monomers generally exhibit a lower elongation at break except for TPUs with a very high hard segment content (Table 2, entry 3 and 6) which exhibit similar elongations at break within experimental error. As expected, Young's moduli decrease with increasing content of polyether soft segment for both polymer series ranging from 17 to $24 \mathrm{MPa}$ for $\mathrm{C}_{19}$-containing polyurethanes and 21 to $36 \mathrm{MPa}$ for $\mathrm{C}_{23}$-containing polyurethanes (Table 2, Figures S15 and S16, Supporting Information). This favorably places the investigated novel materials within the desirable range of 5-700 MPa reported for Young's moduli of commercial TPUs. ${ }^{[24]}$ Comparison to the mid-chain analog TPU$\mathrm{C}_{12} \mathrm{PPDO}_{2000}-59 \mathrm{wt} \%$ (Table 2, entry 7) showed that in materials with a similar portion of soft segment the choice of $\mathrm{C}_{23}$ versus $\mathrm{C}_{12}$ monomers had no significant effect on the Young's modulus with TPU- $\mathrm{C}_{12} \mathrm{PPDO}_{2000}-59 \mathrm{wt} \%$ exhibiting only a slightly higher Young's modulus of $39 \mathrm{MPa}$ compared to TPU-C ${ }_{23} \mathrm{PPDO}_{2000^{-}}$ $63 \mathrm{wt} \%\left(E_{\mathrm{m}}=36 \mathrm{MPa}\right)$, while the ductility improved drastically resulting in an increase of the elongation at break from 280 to $650 \%$. This increase in ductility could not be explained with the 
Table 2. Mechanical properties of polyurethane-polyether copolymers based on long-chain and mid-chain aliphatic hard segments.

\begin{tabular}{|c|c|c|c|c|}
\hline Entry & Polymer & $\begin{array}{l}\text { Young's } \\
\text { mod. }{ }^{a, b)} \\
{[\mathrm{MPa}]}\end{array}$ & $\begin{array}{c}\text { Elongation at } \\
\left.\text { break }^{\mathrm{a}, \mathrm{c}}\right) \\
{[\%]}\end{array}$ & $\begin{array}{c}\text { Residual } \\
\text { strain }^{d} \text { ) } \\
\text { [\%] }\end{array}$ \\
\hline 1 & TPU-C ${ }_{19}$ PPDO $_{2000}-85 \mathrm{wt} \%$ & $17 \pm 3$ & $470 \pm 52$ & 26 \\
\hline 2 & TPU-C ${ }_{19}$ PPDO $_{2000}-78 w t \%$ & $22 \pm 2$ & $450 \pm 49$ & 33 \\
\hline 3 & TPU-C ${ }_{19}$ PPDO $_{2000^{-}} 67 \mathrm{wt} \%$ & $24 \pm 2$ & $270 \pm 70$ & 31 \\
\hline 4 & TPU-C $\mathrm{C}_{23} \mathrm{PPDO}_{2000^{-}} 83 \mathrm{wt} \%$ & $22 \pm 2$ & $440 \pm 29$ & 32 \\
\hline 5 & TPU-C $C_{23}$ PPDO $_{2000}-75 w t \%$ & $21 \pm 4$ & $270 \pm 85$ & 39 \\
\hline 6 & TPU-C ${ }_{23}$ PPDO $_{2000^{-}} 63 \mathrm{wt} \%$ & $36 \pm 2$ & $280 \pm 32$ & 37 \\
\hline 7 & TPU-C ${ }_{12}$ PPDO $_{2000}-59 \mathrm{wt} \%$ & $39 \pm 1$ & $650 \pm 13$ & 29 \\
\hline
\end{tabular}

a) Tensile tests according to ISO $527 / 1-2$, specimen type $5 \mathrm{~A}$ prepared by injection

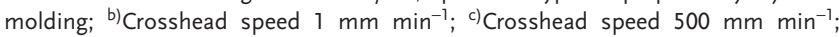
d) Determined from hysteresis experiments after ten cycles at an elongation of $100 \%$ with a crosshead speed of $50 \mathrm{~mm} \mathrm{~min}^{-1}$.

odd-even effect but has to be attributed to increased hydrogen bond formation due to a higher urethane content. ${ }^{[25]}$

In order to assess the elastic properties of the polyurethanepolyether copolymers cyclic hysteresis tests were performed. Test specimens were repeatedly exposed to consecutive cycles of loading to a constant strain of $100 \%$ and unloading. After the first few cycles, where hysteresis is observed and the residual deformation gradually increases, all TPUs exhibit a virtually constant level of recovery. This behavior is typical of thermoplastic elastomers ${ }^{[2,26]}$ and can be ascribed to the adoption of a largely constant structure after an initial change in morphology with alignment of the polymer microstructure. ${ }^{[27]}$ For the segmented polyurethane-polyether copolymers studied here elastomeric behavior is observed for all polymers and residual strains after ten cycles range between 26 and 33\% (Table 2, Figure 4) for $\mathrm{C}_{19}$ copolymers and between 32 and $39 \%$ (Table 2, Figure S17, Supporting Information) for $\mathrm{C}_{23}$ copolymers. For



Figure 4. Stress-strain curves from cyclic tensile tests with a constant strain of $100 \%$ for polyurethane-polyether copolymers TPU- $\mathrm{C}_{19} \mathrm{PPDO}_{2000^{-}}$ $67 \mathrm{wt} \%$ (blue), TPU- $\mathrm{C}_{19} \mathrm{PPDO}_{2000^{-}}-78 \mathrm{wt} \%$ (red), and TPU- $\mathrm{C}_{19} \mathrm{PPDO}_{2000^{-}}$ $85 \mathrm{wt} \%$ (green) (10 cycles). both polymer series the observed residual strain differs only slightly with varying content of hard and soft segment, though the highest level of recovery is observed for polymers without a long-chain diol as an additional component contributing to the crystalline phase. Comparison of TPU- $\mathrm{C}_{23} \mathrm{PPDO}_{2000}-63 \mathrm{wt} \%$ with the mid-chain analog TPU-C ${ }_{12} \mathrm{PPDO}_{2000}-59 \mathrm{wt} \%$ showed that $\mathrm{C}_{12}$ versus $\mathrm{C}_{23}$ monomers results in improved elastic behavior with a decrease of residual strain from 37 to $29 \%$ (Figure S18 and Table 2, entry 6 and 7), indicating that longer methylene sequences and therefore a lower content of urethane groups resulted in a decrease of elasticity.

\subsection{FTIR Spectroscopy}

Attenuated total reflection Fourier transform infrared (ATRFTIR) spectroscopy was used to investigate the composition of the synthesized polyurethanes and determine the relative degree of phase separation. The FTIR spectra show distinct bands related to amide and carbonyl groups at 3334, 1723, and $1683 \mathrm{~cm}^{-1}$, respectively. The lack of an isocyanate peak at $2260 \mathrm{~cm}^{-1}$ and the presence of the amide and carbonyl peaks confirm complete conversion of the monomers to urethane (Figures S19 and S20, Supporting Information).

As the degree of phase separation directly influences the mechanical properties of thermoplastic elastomers, FTIR spectroscopy was used to investigate the microphase morphology and gain further insight into the relation between polymer composition and mechanical properties. Urethane amide groups can form hydrogen bonds with urethane carbonyl groups of hard segments resulting in the formation of hard segment domains as well as with ether groups of soft segments resulting in phase mixing. Therefore, the extent of hydrogen bonding between the urethane amide and carbonyl groups was investigated by FTIR spectroscopy to determine the degree of phase separation.

The shift of the amide band to $3334 \mathrm{~cm}^{-1}$ and the absence of further amide bands at about $3400 \mathrm{~cm}^{-1}$ suggests the presence of only hydrogen bonded amide hydrogens. Closer analysis of the carbonyl region shows the presence of two carbonyl signals at 1723 and $1683 \mathrm{~cm}^{-1}$ (Figure 5 and Figure S21, Supporting Information). Carbonyls that are organized and strongly hydrogen bonded to amides possess restricted vibrational motions resulting in a lower absorption frequency and the observed peak at $1683 \mathrm{~cm}^{-1}$ in the FTIR spectra compares well with a reported value of $1685 \mathrm{~cm}^{-1}$ for strongly hydrogen bonded carbonyl groups. ${ }^{[28]}$ Additional IR bands of carbonyls not involved in hydrogen bonding would be expected at about $1730 \mathrm{~cm}^{-1}$, while carbonyl associated with poorly ordered hydrogen bonding are to be expected at about $1710 \mathrm{~cm}^{-1}$. $\left.3 \mathrm{a}, 28\right]$ Accordingly the carbonyl band at $1723 \mathrm{~cm}^{-1}$ can be assigned to non-hydrogen bonded carbonyl groups. The deviation from literature values can be attributed to differences in the structure of the hard segment components. With increasing content of hard segment the carbonyl band at $1683 \mathrm{~cm}^{-1}$ starts to broaden and peak deconvolution suggests the presence of an additional overlapping signal at about $1702 \mathrm{~cm}^{-1}$ associated with poorly ordered hydrogen bonding. This indicates the formation of larger hard segment domains with imperfect hydrogen bonding 


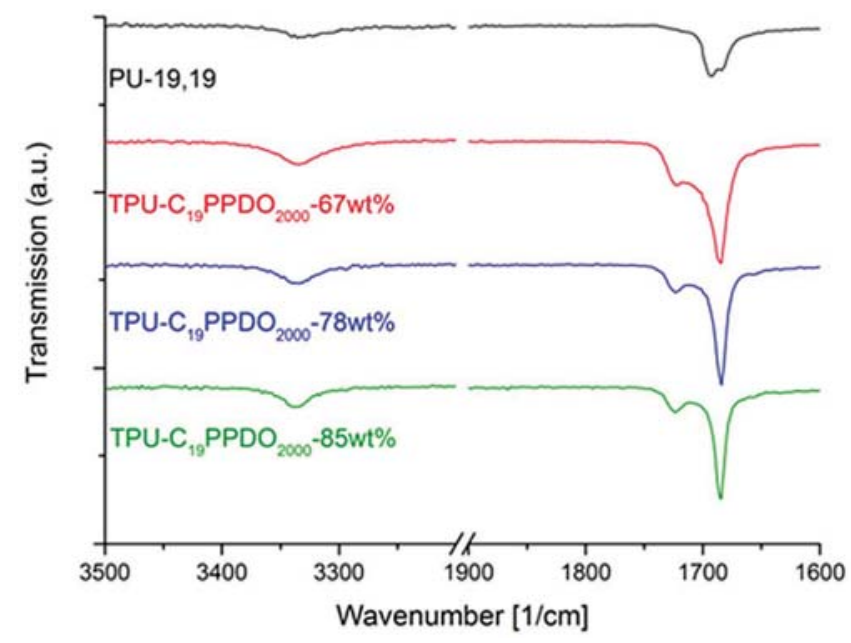

Figure 5. Amide and carbonyl regions of the FTIR spectra of polyurethanes based on $\mathrm{C}_{19}$ monomers.

especially for TPU-C ${ }_{19} \mathrm{PPDO}_{2000^{-}} 67 \mathrm{wt} \%$ and TPU-C ${ }_{23} \mathrm{PPDO}_{2000^{-}}$ 63wt\%. For PU-19,19 and PU-23,23 broad peaks at 1693 and $1685 \mathrm{~cm}^{-1}$ are observed suggesting overlapping of multiple signals (Figure 5 and Figure S21, Supporting Information).

In order to obtain a quantitative measure of the relative amounts of different carbonyl groups present and to determine the extent of phase separation, the carbonyl regime of the FTIR spectra was analyzed by peak deconvolution of the carbonyl absorption bands. The percentage of each carbonyl signal was obtained by comparing the specific peak areas with the total peak area (Table 3). The results indicate the presence of about $15 \%$ of free carbonyl groups for all long-chain TPUs implying a high degree of phase separation of about $85 \%$ regardless of the polymer composition which is only achieved by annealing for other TPUs based on aromatic or cycloaliphatic hard segments. ${ }^{[28 \mathrm{~b}, 29]}$ In comparison, IR analysis of TPU-C ${ }_{12} \mathrm{PPDO}_{2000^{-}}$ 59 wt\% based on mid-chain C12 monomers showed a much lower degree of phase separation of 56\% (Figure S22, Supporting Information, and Table 3, entry 7) indicating that increased chain flexibility due to longer methylene sequences promotes hydrogen bond formation and phase separation.

Table 3. Quantitative analysis of the carbonyl region of FTIR spectra for TPUs by peak deconvolution.

\begin{tabular}{|c|c|c|c|}
\hline \multirow[t]{2}{*}{ Entry } & \multirow[t]{2}{*}{ Polymer } & \multicolumn{2}{|c|}{ Peak area [\%] } \\
\hline & & $\begin{array}{c}\text { Free } \mathrm{C}=\mathrm{O} \text { groups } \\
\quad\left(1723 \mathrm{~cm}^{-1}\right)\end{array}$ & $\begin{array}{l}\text { H-bonded } C=0 \text { groups } \\
\left(1702 \mathrm{~cm}^{-1}+1685 \mathrm{~cm}^{-1}\right)\end{array}$ \\
\hline 1 & TPU- $\mathrm{C}_{19} \mathrm{PPDO}_{2000^{-}-85 \mathrm{wt} \%}$ & 13 & 87 \\
\hline 2 & TPU-C ${ }_{19}$ PPDO $_{2000}-78 w t \%$ & 13 & 87 \\
\hline 3 & TPU-C ${ }_{19}$ PPDO $_{2000^{-}-67 w t} \%$ & 14 & 86 \\
\hline 4 & TPU-C $C_{23}$ PPDO $_{2000^{-}} 83 w t \%$ & 15 & 85 \\
\hline 5 & TPU-C $C_{23}$ PPDO $_{2000}-75 w t \%$ & 15 & 85 \\
\hline 6 & TPU-C ${ }_{23}$ PPDO $_{2000^{-}} 63 w t \%$ & 13 & 87 \\
\hline 7 & TPU-C ${ }_{12}$ PPDO $_{2000}-59 w t \%$ & $54^{\text {a) }}$ & $56^{\text {b) }}$ \\
\hline
\end{tabular}

a) Signal at $1720 \mathrm{~cm}^{-1}$; b) Signal at $1680 \mathrm{~cm}^{-1}$.

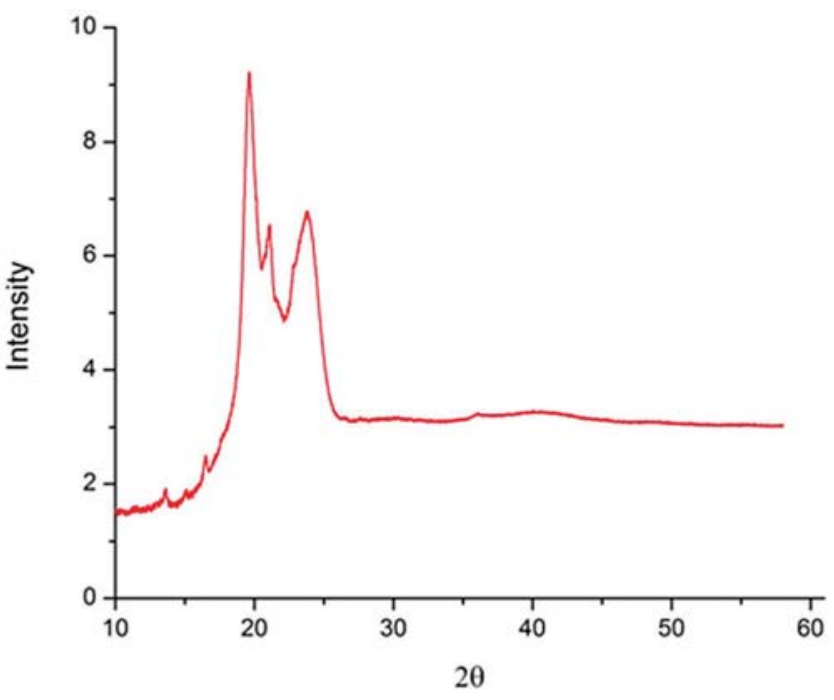

Figure 6. WAXD pattern of PU-19,19.

\subsection{X-Ray Diffraction}

The crystalline solid state structures of the studied novel long-chain polyurethanes were elucidated by WAXS. While long-chain polyesters crystallize in the polyethylene-like orthorhombic structure with ester groups being incorporated in the all-trans hydrocarbon crystal lattice as defects ${ }^{[29]}$ crystalline structures of polyurethanes are dominated by intermolecular hydrogen bonds between urethane groups. ${ }^{[30]}$ The WAXS diffraction patterns of PU-19,19 and PU-23,23 as well as corresponding TPUs displayed peaks at $2 \theta$ angles of $19.6^{\circ}$, $21.1^{\circ}$, and $23.6^{\circ}$ corresponding to $d$-spacings of $4.5,4.2$, and $3.8 \AA$ (Figure 6 and Figure S23, Supporting Information). These values do not concur with orthorhombic polyethylene WAXS diffraction peaks at $d$-spacings of $4.1 \AA\left(d_{110}\right)$ and $3.7 \AA\left(d_{200}\right) \cdot{ }^{[31]}$ In this sense, the long-chain TPUs do not possess a polyethylene-like structure. Rather the $d$-spacings of the two prominent diffraction peaks at $19.6^{\circ}$ and $23.6^{\circ}$ appear to be related to the characteristic two reflection peaks $\left(4.4 \AA\left(d_{100}\right)\right.$ and $\left.3.7 \AA\left(d_{010}\right)\right)$ typically seen for even-even polyamides or polyurethanes in a triclinic crystal phase. ${ }^{[32]}$ The weaker diffraction peak at $21.1^{\circ}$ (4.2 A) corresponds to a pseudohexagonal phase indicating an overall crystal structure composed of triclinic and pseudohexagonal cells. These results correspond to the crystal structures reported for aliphatic polyurethanes based on short-chain diisocyanates and long-chain diols. ${ }^{[30 \mathrm{~b}]}$ Therefore, despite the long methylene sequences, hydrogen bonding is still a dominating factor in the crystallization processes of polyurethanes based on $\mathrm{C}_{19}$ and $\mathrm{C}_{23}$ monomers, resulting in similar crystal structure as for polyurethanes with higher hydrogen-bonding densities.

\section{Experimental Section}

\subsection{Materials and General Considerations}

Methylene chloride was distilled from $\mathrm{CaH}_{2}$. DMF and 1,1,2,2-tetrachloroethane were dried over molecular sieves (3 Å). 
n-Heptane (Emplura 99\%) was purchased from Merck and methanol (99.8\%) from Sigma-Aldrich. All other solvents were used in technical grade as received. Tetrabromomethane (98\%) was purchased from ABCR, triphenylphosphine (99\%) from Acros Organics, potassium cyanate (96\%) from Sigma Aldrich, and $N, N^{\prime}$-di-2-naphthyl-1,4-phenylenediamine (>96\%) from TCI Europe. Poly(trimethylene glycol) with a number average molecular mass of $M_{n}=2000$ kindly donated by Allessa $\mathrm{GmbH}$ was degassed prior to use. Dimethyl-1,23-tricosanedioate ${ }^{[13]}$ and tricosane-1,23-dio ${ }^{[14]}$ as well as dimethyl-1,19-nonadecanedioate, ${ }^{[13]}$ and nonadecane-1,19-diol ${ }^{[14]}$ were prepared from methyl erucate and methyl oleate, respectively, according to previously reported literature procedures. All reactions were carried out under standard Schlenk conditions under a nitrogen atmosphere.

\subsection{Characterization}

NMR spectra were recorded on a Varian Inova 400 and a Bruker Avance 400 spectrometer. ${ }^{1} \mathrm{H}$ and ${ }^{13} \mathrm{C}$ chemical shifts were referenced to the solvent signals. DSC analyses were performed on a Netzsch Phoenix 204 F1 instrument with a heating and cooling rate, respectively, of $10 \mathrm{~K} \mathrm{~min}^{-1}$ in a temperature range of -50 to $160{ }^{\circ} \mathrm{C}$. Data reported are from second heating cycles. GPC measurements were carried out on a Polymer Laboratories PL-GPC 50 with two PLgel $5 \mu \mathrm{m}$ MIXED-C columns in THF at $50{ }^{\circ} \mathrm{C}$ against polystyrene standards with refractive index detection or on a Polymer Laboratories 220 instrument equipped with Olexis columns with differential refractive index, viscosity, and light-scattering $\left(15^{\circ}\right.$ and $90^{\circ}$ ) detectors in 1,2,4-trichlorobenzene at $160^{\circ} \mathrm{C}$ against linear polyethylene standards. Tensile testing was performed on dogbone-shaped sample bars $\left(75 \times 12.5 \times 2 \mathrm{~mm}^{3}\right.$; ISO 527-2, type 5A) which were prepared using a HAAKE Minijet II (Thermo Scientific) piston injection molder. $0.1 \mathrm{wt} \%$ of $N, N^{\prime}$-di-2-naphthyl-1,4-phenylenediamine were employed as a stabilizer. After preconditioning the samples overnight tensile tests were performed on a Zwick 1446 Retroline tC II instrument according to ISO 527 (crosshead speed $500 \mathrm{~mm} \mathrm{~min}^{-1}$, with a determination of the Young's modulus at a crosshead speed of $1 \mathrm{~mm} \mathrm{~min}{ }^{-1}$ ). The Zwick test Xpert software version 11.0 was used to collect and analyze the data. Young's modulus, yield stress, yield strain, tensile stress at break, and tensile strain at break were obtained by averaging the data from several test specimens. Cyclic hysteresis tests were performed on dogbone-shaped sample bars $\left(75 \times 12.5 \times 2 \mathrm{~mm}^{3}\right.$; ISO 527-2, type 5A). The test specimens were repeatedly exposed to consecutive cycles of loading and unloading to a constant strain of $100 \%$ with a constant crosshead speed of $50 \mathrm{~mm}$ $\mathrm{min}^{-1}$. The recovery was measured by observing the residual strain after ten cycles. ATR-FTIR spectra were redorded on a PerkinElmer Spectrum100 FTIR Spectrometer equipped with a Universal ATR Sampling Accessory. FTIR scans were collected on injection molded dogbone-shaped sample bars $\left(75 \times 12.5 \times 2 \mathrm{~mm}^{3}\right.$; ISO 527-2, type 5A). The frequency range covered was from 4000 to $650 \mathrm{~cm}^{-1}$ by averaging 32 scans at a resolution of $2 \mathrm{~cm}^{-1}$. Wide angle X-ray diffraction (WAXD) was performed on a Bruker AXS D8 Advance diffractometer using $\mathrm{CuK} \alpha 1$ radiation. Diffraction patterns were recorded in the range $10^{\circ}-60^{\circ} 2 \theta$, at $25^{\circ} \mathrm{C}$. Polymer samples for WAXD were prepared by crystallization from hot tetrachloroethane.

\subsection{Monomer Synthesis}

\subsubsection{1,19-Dibromononadecane}

1,19-Nonadecanediol (11.4 g, $37.9 \mathrm{mmol}$ ) and $\mathrm{CBr}_{4}$ (31.4 g, $94.8 \mathrm{mmol}$ ) were suspended in $500 \mathrm{~mL}$ methylene chloride and triphenylphosphine $(26.9 \mathrm{~g}, 102.4 \mathrm{mmol})$ was slowly added as a solid over $30 \mathrm{~min}$. The yellow solution was then heated to $50{ }^{\circ} \mathrm{C}$ for $1 \mathrm{~h}$ and afterward stirred at room temperature overnight. Then $100 \mathrm{~mL}$ methanol and $10 \mathrm{~mL}$ water were added and the solution stirred for $10 \mathrm{~min}$ at room temperature. The solvent was removed to obtain a beige solid, which was dissolved in $200 \mathrm{~mL} n$-pentane and methanol. After extraction with pentane $(3 \times 200 \mathrm{~mL})$ the combined pentane phases were washed once with $200 \mathrm{~mL}$ of water and the solvent then removed. Column chromatography with methylene chloride and subsequent crystallization from ethanol/ethylacetat (4:1) yielded $14.5 \mathrm{~g}$ of a white solid (34.0 mmol, 88\%). ${ }^{.7]}$

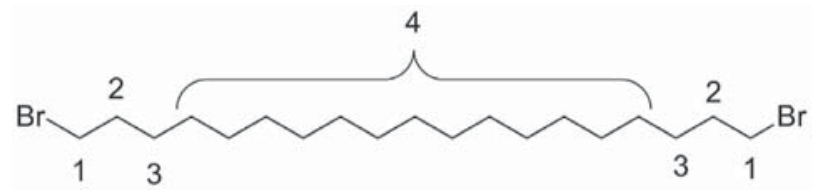

${ }^{1} \mathrm{H}$ NMR $\left(\mathrm{CDCl}_{3}, 25^{\circ} \mathrm{C}, 400 \mathrm{MHz}\right) \delta 3.41\left(\mathrm{t},{ }^{3} J_{\mathrm{H}-\mathrm{H}}=7.0 \mathrm{~Hz}\right.$, $4 \mathrm{H}, \mathrm{H}-1$ ), 1.85 (qint, ${ }^{3} J_{\mathrm{H}-\mathrm{H}}=7.0 \mathrm{~Hz}, 4 \mathrm{H}, \mathrm{H}-2$ ), 1.42 (quint, $\left.{ }^{3} J_{\mathrm{H}-\mathrm{H}}=7.0 \mathrm{~Hz}, 4 \mathrm{H}, \mathrm{H}-3\right), 1.35-1.21$ (m, 26H, H-4). ${ }^{13} \mathrm{C} \mathrm{NMR}$ $\left(101 \mathrm{MHz}, \mathrm{CDCl}_{3}\right.$ ) $\delta 34.2$ (C-1), 33.0 (C-2), 29.8-29.6 (C-4), 28.9 (C-4), 28.3 (C-3).

\subsubsection{1,23-Dibromotricosane}

1,23-Dibromotricosane was prepared analogous to the aforementioned procedure. The desired product was isolated as a white solid in $90 \%$ yield. ${ }^{[7]}$

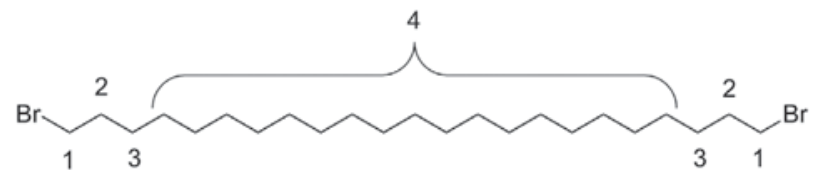

${ }^{1} \mathrm{H} \mathrm{NMR}\left(\mathrm{CDCl}_{3}, 25{ }^{\circ} \mathrm{C}, 400 \mathrm{MHz}\right) \delta 3.41\left(\mathrm{t},{ }^{3} \mathrm{~J}_{\mathrm{H}-\mathrm{H}}=7.0 \mathrm{~Hz}\right.$, $4 \mathrm{H}, \mathrm{H}-1$ ), 1.85 (qint, ${ }^{3} J_{\mathrm{H}-\mathrm{H}}=7.0 \mathrm{~Hz}, 4 \mathrm{H}, \mathrm{H}-2$ ), 1.42 (quint, $\left.{ }^{3} J_{\mathrm{H}-\mathrm{H}}=7.0 \mathrm{~Hz}, 4 \mathrm{H}, \mathrm{H}-3\right), 1.35-1.21$ (m, 34H, H-4). ${ }^{13} \mathrm{C} \mathrm{NMR}$ $\left(101 \mathrm{MHz}, \mathrm{CDCl}_{3}\right.$ ) $\delta 34.2$ (C-1), 33.0 (C-2), 29.8-29.6 (C-4), 28.9 (C-4), 28.3 (C-3).

\subsubsection{1,19-Diisocyanatononadecane}

1,19-Dibromononadecane (3.0 g, $7.0 \mathrm{mmol})$ was dissolved in $50 \mathrm{~mL}$ DMF and the solution heated to $120^{\circ} \mathrm{C}$. Potassium cyanate $(2.9 \mathrm{~g}, 35.2 \mathrm{mmol})$ was added and the suspension stirred at $120{ }^{\circ} \mathrm{C}$ for $35 \mathrm{~min}$. Then the reaction mixture was 
extracted with $n$-heptane $(3 \times 100 \mathrm{~mL})$ and the combined $n$-heptane phases washed with water. After drying over $\mathrm{MgSO}_{4}$, filtration and removing of the solvent the crude product was distilled using a sublimation apparatus with a cold finger $\left(130{ }^{\circ} \mathrm{C}\right.$, $0.06 \mathrm{mbar}$ ) to give $860 \mathrm{mg}$ of a white solid (2.5 mmol, $35 \%)$.

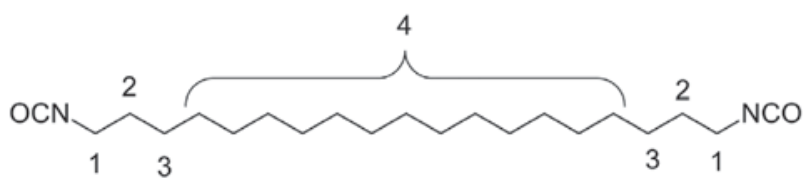

${ }^{1} \mathrm{H}$ NMR $\left(\mathrm{CDCl}_{3}, 25{ }^{\circ} \mathrm{C}, 400 \mathrm{MHz}\right) \delta 3.29\left(\mathrm{t},{ }^{3} J_{\mathrm{H}-\mathrm{H}}=6.7\right.$ $\mathrm{Hz}, 4 \mathrm{H}, \mathrm{H}-1$ ), 1.61 (quint, ${ }^{3} \mathrm{H}_{\mathrm{H}-\mathrm{H}}=6.7 \mathrm{~Hz}, 4 \mathrm{H}, \mathrm{H}-2$ ), $1.41-1.33$ (m, 4H, H-3), 1.33-1.21 (m, 26H, H-4). ${ }^{13} \mathrm{C}$ NMR (101 MHz, $\left.\mathrm{CDCl}_{3}\right) \delta 122.0(\mathrm{NCO}), 43.1$ (C-1), 31.4 (C-2), 29.8-29.5 (C-4), 29.1 (C-4), 26.7 (C-3).

\subsubsection{1,23-Diisocyanatotricosane}

1,23-Diisocyanatotricosane was prepared analogous to the aforementioned procedure. The desired product was isolated by distillation $\left(140{ }^{\circ} \mathrm{C}, 0.06\right.$ mbar) to give a white solid in $40 \%$ yield.

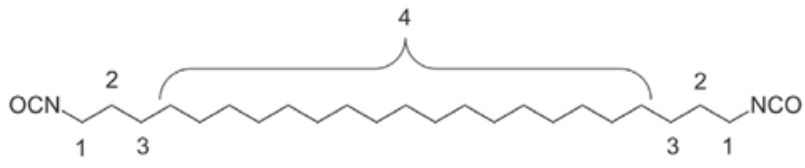

${ }^{1} \mathrm{H}$ NMR $\left(\mathrm{CDCl}_{3}, 25{ }^{\circ} \mathrm{C}, 400 \mathrm{MHz}\right) \delta 3.29\left(\mathrm{t},{ }^{3} \mathrm{~J}_{\mathrm{H}-\mathrm{H}}=6.7\right.$ $\mathrm{Hz}, 4 \mathrm{H}, \mathrm{H}-1$ ), 1.61 (quint, ${ }^{3} \mathrm{~J}_{\mathrm{H}-\mathrm{H}}=6.7 \mathrm{~Hz}, 4 \mathrm{H}, \mathrm{H}-2$ ), $1.42-1.33$ (m, 4H, H-3), 1.33-1.21 (m, 34H, H-4). ${ }^{13} \mathrm{C}$ NMR (101 MHz, $\left.\mathrm{CDCl}_{3}\right) \delta 122.1$ (NCO), 43.1 (C-1), 31.4 (C-2), 29.8-29.6 (C-4), 29.1 (C-4), 26.7 (C-3).

\subsubsection{General Polymerization Procedure}

After weighing in the desired amount of freshly distilled longchain diisocyanate, long-chain diol (optional), and $\mathrm{PPDO}_{2000}$ the mixture was degassed and dissolved in $20 \mathrm{~mL}$ of DMF (for TPU-C ${ }_{19} \mathrm{PPDO}_{2000^{-}} 85 \mathrm{wt} \%$ ) or 1,1,2,2-tetrachloroethane (for all other polyurethanes). Then $0.5 \mathrm{~mol} \%$ of dibutyltin dilaurate was added and the solution heated to $80^{\circ} \mathrm{C}$ and stirred for $24 \mathrm{~h}$. The reaction was stopped by adding $5 \mathrm{~mL}$ of methanol and after stirring for another $15 \mathrm{~min}$ the polymer was precipitated by pouring the reaction mixture into methanol. After filtration the white rubber-like polymer was dried in vacuo at $50{ }^{\circ} \mathrm{C}$ for $48 \mathrm{~h}$.

\section{Conclusions}

In summary, two novel linear long-chain diisocyanates 1,19-diisocyanatononadecane and 1,23-diisocyanatotricosane were successfully synthesized from oleic acid and erucic acid esters via nucleophilic substitution. Polyaddition of these biobased long-chain diisocyanates and their corresponding longchain diols with diol-terminated $\mathrm{PPDO}_{2000}$ yielded entirely bio-based transparent polyurethane-polyether copolymers with molecular weights up to $M_{\mathrm{n}} 5.0 \times 10^{4} \mathrm{~g} \mathrm{~mol}^{-1}$. The long-chain aliphatic polyurethane segments provide physical crosslinking via hydrogen bonding resulting in melting points up to $116{ }^{\circ} \mathrm{C}$ and elastomeric behavior of these thermoplastic materials. A particularly high recovery was observed if no additional long-chain diol was incorporated. FTIR spectroscopy showed well-separated microphase morphologies and strongly hydrogen-bonded hard segments. Comparison to an analogous mid-chain monomer based polyurethane-polyether copolymer showed that applying long-chain monomers and the resulting lower content of urethane groups in the copolymer resulted in lower melting points and decreased ductility and elasticity but promoted phase separation.

\section{Acknowledgements}

B.S. is grateful for a stipend provided by the State of Baden-Württemberg through the Landesgraduiertenförderungsgesetz.

\section{Conflict of Interest}

The authors declare no conflict of interest.

\section{Keywords}

catalysis, fatty acid, polyurethane, renewable ressource, thermoplastic elastomer

[1] a) G. Woods, The ICI Polyurethanes Book, Wiley, New York 1990; b) M. D. Lelah, S. L. Cooper, Polyurethanes in Medicine, CRC Press, Boca Raton, FL 1986; c) Block Polymers (Ed: S. L. Aggarwal), Plenum, New York 1970.

[2] G. Holden, H. R. Kricheldorf, R. P. Quirk, Thermoplastic Elastomers, Hanser, Munich, Germany 2004.

[3] a) Z. S. Petrovic, J. Ferguson, Prog. Polym. Sci. 1991, 16, 695; b) P. Król, Prog. Mater Sci. 2007, 52, 915; c) Y. He, D. Xie, X. Zhang, J. Mater. Sci. 2014, 49, 7339.

[4] D. K. Chattopadhyay, D. C. Webster, Prog. Polym. Sci. 2009, 34, 1068.

[5] a) D. Randall, S. Lee, The Polyurethanes Book, Wiley, New York 2002; b) C. Hepburn, Polyurethane Elastomers, Springer, Berlin 2012.

[6] a) L. Hojabri, X. Kong, S. S. Narine, J. Polym. Sci., Part A: Polym. Chem. 2010, 48, 3302; b) E. Perry, J. Savory, J. Appl. Polym. Sci. 1967, 11, 2473; c) Y. Iwakura, K. Uno, K. Suzuki, K. Fujii, Nippon Kageku Zasshi 1957, 78, 1507; d) Y. Iwakura, K. Uno, K. Suzuki, K. Fujii, Nippon Kageku Zasshi 1957, 78, 1511. e) S. Schmidt, F. J. Gatti, M. Luitz, B. S. Ritter, B. Bruchmann, R. Mülhaupt, Macromolecules 2017, 50, 2296. 
[7] P. Roesle, F. Stempfle, S. K. Hess, J. Zimmerer, C. Río Bártulos, B. Lepetit, A. Eckert, P. G. Kroth, S. Mecking, Angew. Chem., Int. Ed. 2014, 53, 6800 .

[8] a) U. Schörken, P. Kempers, Eur. J. Lipid Sci. Technol. 2009, 111, 627; b) S. Schaffer, T. Haas, Org. Process Res. Dev. 2014, 18, 752; c) W. Lu, J. E. Ness, W. Xie, X. Zhan, J. Minshull, R. A. Gross, J. Am. Chem. Soc. 2010, 132, 15451.

[9] a) M. B. Dinger, J. C. Mol, Adv. Synth. Catal. 2002, 344, 671; b) H. Ngo, K. Jones, T. Foglia, J. Am. Oil Chem. Soc. 2006, 83, 629.

[10] a) C. Jiménez-Rodriguez, G. R. Eastham, D. J. Cole-Hamilton, Inorg. Chem. Commun. 2005, 8, 878; b) P. Roesle, C. J. Dürr, H. M. Möller, L. Cavallo, L. Caporaso, S. Mecking, J. Am. Chem. Soc. 2012, 134, 17696.

[11] F. Stempfle, P. Orgmann, S. Mecking, Chem. Rev. 2016, 116, 4597.

[12] a) O. Kreye, H. Mutlu, M. A. R. Meier, Green Chem. 2013, 15, 1431; b) L. Maisonneuve, T. Lebarbé, E. Grau, H. Cramail, Polym. Chem. 2013, 4, 5472; c) L. Maisonneuve, O. Lamarzelle, E. Rix, E. Grau, H. Cramail, Chem. Rev. 2015, 115, 12407.

[13] F. Stempfle, B. S. Ritter, R. Mülhaupt, S. Mecking, Green Chem. 2014, 16, 2008.

[14] D. Quinzler, S. Mecking, Angew. Chem., Int. Ed. 2010, 49, 4306.

[15] W. D. Schaeffer, (Union Oil Company of California), US 3017420, 1962.

[16] a) A. S. More, T. Lebarbé, L. Maisonneuve, B. Gadenne, C. Alfos, H. Cramail, Eur. Polym. J. 2013, 49, 823; b) C. Fu, Z. Zheng, Z. Yang, Y. Chen, L. Shen, Prog. Org. Coat. 2013, 77, 53.

[17] M. Unverferth, O. Kreye, A. Prohammer, M. A. R. Meier, Macromol. Rapid Commun. 2013, 34, 1569.

[18] a) Press release by DuPont, Tate \& Lyle of June 8, 2007; b) M. A. Harmer, D. C. Confer, C. K. Hoffman, S. C. Jackson, A. Y. Liauw, A. R. Minter, E. R. Murphy, R. E. Spence, H. B. Sunkara, Green Chem. 2010, 12, 1410.

[19] F. Stempfle, B. Schemmer, A.-L. Oechsle, S. Mecking, Polym. Chem. 2015, 6, 7133.

[20] R. L. McKiernan, S. P. Gido, J. Penelle, Polymer 2002, 43, 3007.
[21] J. E. O'Gara, K. B. Wagener, S. F. Hahn, Makromol. Chem., Rapid Commun. 1993, 14, 657 .

[22] a) R. M. Versteegen, R. P. Sijbesma, E. W. Meijer, Angew. Chem., Int. Ed. 1999, 38, 2917; b) S. Neffgen, J. Kušan, T. Fey, H. Keul, H. Höcker, Macromol. Chem. Phys. 2000, 201, 2108.

[23] Y. Camberlin, J. P. J. Pascualt, J. Polym. Sci., Polym. Chem. Ed. 1983, $21,415$.

[24] T. Ouhadi, S. Abdou-Sabet, H.-G. Wussow, L. M. Ryan, L. Plummer, F. E. Baumann, J. Lohmar, H. F. Vermeire, F. L. G. Malet, in Ullmann's Encyclopedia of Industrial Chemistry (Eds: W. Gerhartz, B. Elvers), Wiley-VCH, Weinheim 2014, p. 1.

[25] L. Hojabri, X. Kong, S. Narine, Biomacromolecules 2009, 10, 884

[26] A. Schmidt, W. S. Veeman, V. M. Litvinov, W. Gabriëlse, Macromolecules 1998, 31, 1652

[27] a) M. A. Hood, B. Wang, J. M. Sands, J. J. La Scala, F. L. Beyer, C. Y. Li, Polymer 2010, 51, 2191; b) I. Yilgor, E. Yilgor, I. G. Guler, T. C. Ward, G. L. Wilkes, Polymer 2006, 47, 4105.

[28] a) R. Hernandez, J. Weksler, A. Padsalgikar, T. Choi, E. Angelo, J. S. Lin, L.-C. Xu, C. A. Siedlecki, J. Runt, Macromolecules 2008, 41, 9767; b) I. Yilgor, E. Yilgor, G. L. Wilkes, Polymer 2015, 58, A1.

[29] a) P. Ortmann, S. Mecking, Macromolecules 2013, 46, 7213; b) J. Trzaskowski, D. Quinzler, C. Bährle, S. Mecking, Macromol. Rapid Commun. 2011, 32, 1352; c) C. Le Fevere De Ten Hove, J. Penelle, D. A. Ivanov, A. M. Jonas, Nat. Mater. 2004, 3,33 .

[30] a) Y. Saito, K. Hara, S. Kinoshita, Polym. J. 1982, 14, 19; b) R. L. McKiernan, A. M. Heintz, S. L. Hsu, E. D. T. Atkins, J. Penelle, S. P. Gido, Macromolecules 2002, 35, 6970; c) A. M. Heintz, R. L. McKiernan, S. P. Gido, J. Penelle, S. L. Hsu, S. Sasaki, A. Takahara, T. Kajiyama, Macromolecules 2002, 35, 3117; d) R. L. McKiernan, P. Sikorski, E. D. T. Atkins, S. P. Gido, J. Penelle, Macromolecules 2002, 35, 8433.

[31] C. W. Bunn, Trans. Faraday Soc. 1939, 35, 482.

[32] C. W. Bunn, E. V. Garner, Proc. R. Soc. London, Part A 1947, 189, 39. 